\title{
Synthesis and photodegradation studies of analogues of muscle relaxant 1,4-dihydropyridine compounds
}

\author{
MIYASE GÖZDE GÜNDÜZ1 \\ GAETANO RAGNO ${ }^{2}$ \\ RAHIME ŞIMŞEK ${ }^{1}$ \\ MICHELE DE LUCA ${ }^{2}$ \\ CIHAT SSAFAK ${ }^{1}$ \\ FEDORA GRANDE ${ }^{2}$ \\ AHMED EL-KHOULY ${ }^{1}$ \\ FATMA İSLI ${ }^{3}$ \\ SENIZ YILDIRIM ${ }^{3}$ \\ GÖKÇE SEVIM ÖZTÜRK FINCAN ${ }^{3}$ \\ GIUSEPPINA IOELE2 $2^{*}$ \\ ${ }^{1}$ Department of Pharmaceutical \\ Chemistry \\ Faculty of Pharmacy, Hacettepe \\ University, 06100, Ankara, Turkey \\ ${ }^{2}$ Department of Pharmacy, Health and \\ Nutritional Sciences \\ University of Calabria, 87036 Rende (CS) \\ Italy \\ ${ }^{3}$ Department of Pharmacology \\ Faculty of Medicine, Gazi University \\ 06560, Ankara, Turkey \\ Accepted May 10, 2017 \\ Published online June 14, 2017
}

\begin{abstract}
This paper describes the synthesis of 1,4-dihydropyridine compounds (DHPs) endowed with good muscle relaxant activity and stability to light. Six new condensed DHPs were synthesized by the microwave irradiation method. A long-chain ester moiety [2-(methacryloyloxy)ethyl] and various substituents on the phenyl ring were demonstrated to affect the muscle relaxant activity occurring in isolated rabbit gastric fundus smooth muscle strips. Forced photodegradation conditions were applied to the molecules according to the ICH rules. The degradation profile of the drugs was monitored by spectrophotometry coupled with the multivariate curve resolution technique. Formation of the oxidized pyridine derivative was observed for all the studied DHPs, except for one compound, which showed very fast degradation and formation of a second photoproduct. Pharmacological tests on the molecules showed a good muscle relaxing effect, with a mechanism similar to that of nifedipine, however, proving to be more stable to light.
\end{abstract}

Keywords: 1,4-dihydropyridine compounds, muscle relaxant, drug design, structure activity relationship, photostability, MCR analysis

1,4-Dihydropyridines (DHPs) are an important class of calcium channel blockers. These compounds are considered to be vital drugs against cardiovascular diseases such as hypertension and angina pectoris (1). Besides the main cardiovascular actions, the 1,4DHP nucleus has been shown to possess potential anti-tuberculosis, antioxidant, analgesic, anti-tumor and anti-microbial activity (2-4).

Numerous changes have been proposed for the basic structure of the parent drug nifedipine (NIF) in order to strengthen the modulating effects on calcium channels $(5,6)$. According to several structure-activity relationship studies, the 1,4-dihydropyridine ring with unsubstituted nitrogen and aryl ring at C-4 are essential for pharmacological activity

*Correspondence; e-mail: giuseppina.ioele@unical.it 
(7). The presence of one or more electron-attracting substituents at the ortho- or meta-position of the phenyl ring increases the activity (8). Ester groups at C-3 and C-5 are in turn very important for modulating activity and tissue selectivity. Most attempts to optimize the activity of DHPs are focused on these ester groups. In condensed 1,4-DHPs, modification of the ester moiety is essential in blocking the calcium channels $(9,10)$. Recent studies describe the importance of long chain esters with aromatic/hydrophobic groups in obtaining potent calcium blockers such as nicardipine, azelnidipine and cilnidipine (4). Fused DHPs obtained by introducing the DHP ring into condensed ring systems have shown good calcium antagonistic effects $(11,12)$. Recently, a series of new condensed 1,4-DHP derivatives, having a dimethyl-substituted cyclohexane ring fused with a 3-pyridylmethyl moiety, have been synthesized by our research groups $(13,14)$.

In this work, a series of new condensed DPH analogues were synthetized by the microwave irradiation method. The muscle relaxant activity of these compounds was evaluated on isolated rabbit gastric fundus smooth muscle strips and compared to that of NIF. Due to the well-known photo-lability of DHPs (15-18), the synthesized compounds were subjected to photodegradation tests (19). Concentration of parent compounds and by-products was calculated by multivariate curve resolution-alternating least squares (MCR-ALS) applied to the spectral data (20-22).

\section{EXPERIMENTAL}

\section{Chemicals and materials}

All chemicals used were purchased from Aldrich and Fluka (USA) and were used without further purification. Reactions to obtain the target compounds were carried out in a Discover microwave apparatus (CEM, USA). Purity of the obtained compounds was initially checked using thin layer chromatography (TLC) on Merck aluminium sheets (Germany), silica gel $60 \mathrm{~F}_{254}$, mobile phase ethyl acetate-hexane (1:1), and UV absorbing spots were detected under short-wavelength $(254 \mathrm{~nm}$ ) light (Camag UV Cabinet, Germany). Melting points were determined on a Thomas Hoover capillary melting point apparatus (USA) and were uncorrected. Infrared spectra (IR) were obtained on a Perkin Elmer Spectrum BX FT-IR (UK) equipped with MIRacle ATR accessory (PIKE Technologies, USA) and were reported in $\mathrm{cm}^{-1} .{ }^{1} \mathrm{H} \mathrm{NMR}$ and ${ }^{13} \mathrm{C}$ NMR spectra were recorded in dimethyl sulfoxide (DMSO- $d_{6}$ ) solutions on a Varian Mercury 400, $400 \mathrm{MHz}$ high performance digital FT-NMR spectrometer (USA) using tetramethylsilane (TMS) as internal standard. Chemical shifts were reported in parts per million (ppm). ESI-MS spectra were measured on a Micromass ZQ-4000 single quadrupole mass spectrometer (Waters, USA). Elemental analyses $(\mathrm{C}, \mathrm{H}, \mathrm{N})$ were performed on a Leco CHNS-932 elemental analyzer (USA).

Photodegradation tests were performed using a light cabinet Suntest CPS+ (Heraeus, Italy). During the photodegradation experiments, UV spectra were recorded by means of a Perkin-Elmer Lambda 40P spectrophotometer (Artisan Technology Group, USA). UV WinLab $^{\circledR}$ (Perkin-Elmer, USA) and Matlab ${ }^{\circledR}$ computer environment (Mathwork Inc., version 7, USA) software permitted spectral acquisition and multivariate analysis, resp. 
M. G. Gündüz et al.: Synthesis and photodegradation studies of analogues of muscle relaxant 1,4-dihydropyridine compounds, Acta Pharm. 67 (2017) 341-355.

Synthesis of 2-(methacryloyloxy)ethyl-2,6,6-trimethyl-4-substituted phenyl-5-oxo1,4,5,6,7,8-hexahydroquinoline-3-carboxylates. General procedure

General procedure for the one-pot synthesis of 1,4-DHP derivatives via Hantzsch reaction was as follows: $2 \mathrm{mmol}$ 4,4-dimethyl-1,3-cyclohexanedione, $2 \mathrm{mmol}$ substituted benzaldehyde, $2 \mathrm{mmol}$ 2-(methacryloyloxy)ethyl acetoacetate and $10 \mathrm{mmol}$ ammonium acetate were dissolved in a 35-mL microwave pressure vial in ethanol and subjected to microwave irradiation (power $75 \mathrm{~W}$, maximum temperature $150^{\circ} \mathrm{C}$ ) for 10 minutes. Reaction progress was monitored by TLC. After completion of the reaction, the mixture was dried under reduced pressure and the resulting precipitate was recrystallized from the dichloromethane/ether mixture. All physicochemical and spectral data of the synthesized compounds are listed in Table I.

2-(Methacryloyloxy)ethyl 2,6,6-trimethyl-4-(2-fluorophenyl)-5-oxo-1,4,5,6,7,8-hexahydroquinoline-3-carboxylate (DHP1). - The compound was obtained by the reaction of 4,4-dimethyl-1,3-cyclohexanedione (280 mg), 2-fluorobenzaldehyde (248 mg), 2-(methacryloyloxy)ethyl acetoacetate $(428 \mathrm{mg})$ and ammonium acetate $(770 \mathrm{mg})$ in ethanol.

2-(Methacryloyloxy)ethyl 2,6,6-trimethyl-4-(3-chlorophenyl)-5-oxo-1,4,5,6,7,8-hexahydroquinoline-3-carboxylate (DHP2). - The compound was obtained by the reaction of 4,4-dimethyl-1,3-cyclohexanedione (280 mg), 3-chlorobenzaldehyde (280 mg), 2-(methacryloyloxy)ethyl acetoacetate $(428 \mathrm{mg})$ and ammonium acetate $(770 \mathrm{mg})$ in ethanol.

2-(Methacryloyloxy)ethyl 2,6,6-trimethyl-4-(3-fluorophenyl)-5-oxo-1,4,5,6,7,8-hexahydroquinoline-3-carboxylate (DHP3). - The compound was obtained by the reaction of 4,4-dimethyl-1,3-cyclohexanedione $(280 \mathrm{mg})$, 3-fluorobenzaldehyde $(248 \mathrm{mg})$, 2-(methacryloyloxy)ethyl acetoacetate $(428 \mathrm{mg})$ and ammonium acetate $(770 \mathrm{mg})$ in ethanol.

2-(Methacryloyloxy)ethyl 2,6,6-trimethyl-4-(3-nitrophenyl)-5-oxo-1,4,5,6,7,8-hexahydroquinoline-3-carboxylate (DHP4). - The compound was obtained by the reaction of 4,4-dimethyl1,3-cyclohexanedione (280 mg), 3-nitrobenzaldehyde (302 mg), 2-(methacryloyloxy)ethyl acetoacetate $(428 \mathrm{mg})$ and ammonium acetate $(770 \mathrm{mg})$ in ethanol.

2-(Methacryloyloxy)ethyl 2,6,6-trimethyl-4-(3-cyanophenyl)-5-oxo-1,4,5,6,7,8-hexahydroquinoline-3-carboxylate (DHP5). - The compound was obtained by the reaction of 4,4-dimethyl-1,3-cyclohexanedione (280 mg), 3-cyanobenzaldehyde (262 mg), 2-(methacryloyloxy)ethyl acetoacetate $(428 \mathrm{mg}$ ) and ammonium acetate $(770 \mathrm{mg})$ in ethanol.

2-(Methacryloyloxy)ethyl 2,6,6-trimethyl-4-(2,3-dichlorophenyl)-5-oxo-1,4,5,6,7,8-hexahydroquinoline-3-carboxylate (DHP6). - The compound was obtained by the reaction of 4,4-dimethyl-1,3-cyclohexanedione $(280 \mathrm{mg})$, 2,3-dichlorobenzaldehyde $(350 \mathrm{mg}), 2$-(methacryloyloxy)ethyl acetoacetate $(428 \mathrm{mg})$ and ammonium acetate $(770 \mathrm{mg})$ in ethanol.

\section{Pharmacological evaluation}

$\mathrm{N} \omega$-nitro-L-arginine-methyl ester (L-NAME) hydrochloride, tetraethylammonium chloride, guanethidine and NIF were dissolved in distilled water. Synthesized compounds and indomethacin were dissolved in DMSO.

New Zealand white rabbits, weighing $2.5-3 \mathrm{~kg}$, were used in the study. Rabbits were sacrificed by intravenous injection of sodium pentobarbital ( $\left.30-40 \mathrm{mg} \mathrm{kg}^{-1} \mathrm{bm}\right)$, followed by removal of the stomach through abdominal incision. The fundal part of the stomach 


\begin{tabular}{|c|c|c|c|c|c|c|}
\hline \multirow{3}{*}{ 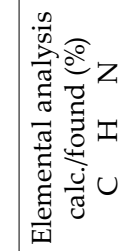 } & $\Rightarrow \vec{c}$ & 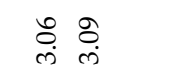 & $\stackrel{\Rightarrow}{\oplus}$ & 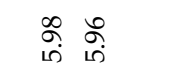 & 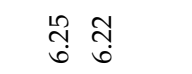 & $\begin{array}{ll}\stackrel{H}{\infty} & \infty \\
i & \infty \\
i\end{array}$ \\
\hline & 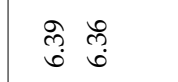 & 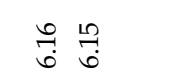 & ले ఫ़े & 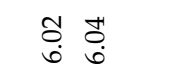 & 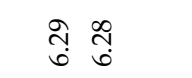 & 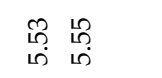 \\
\hline & 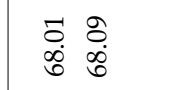 & 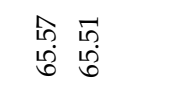 & $\begin{array}{ll}5 & n \\
\infty & 0 \\
0 & 0 \\
0 & 0\end{array}$ & 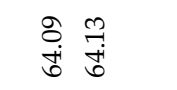 & $\begin{array}{l}80 \\
\stackrel{0}{0} \\
\dot{0}\end{array}$ & $\begin{array}{l}\infty \\
\text { oे } \\
\text { bे } \\
\text { bे }\end{array}$ \\
\hline $\begin{array}{l}\frac{\pi}{\Sigma} \\
\text { E } \\
\sum\end{array}$ & 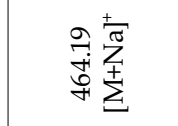 & 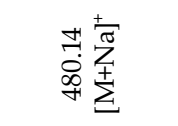 & 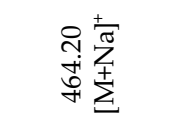 & 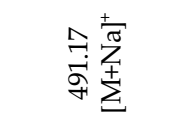 & 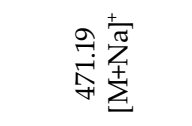 & 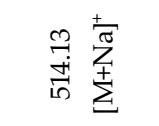 \\
\hline 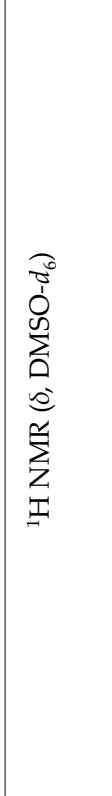 & 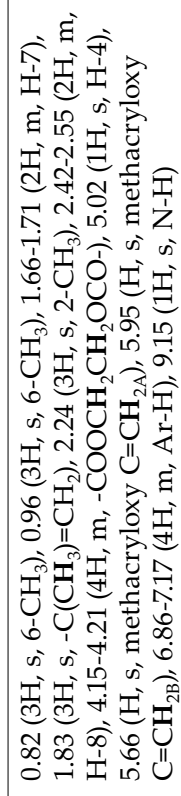 & 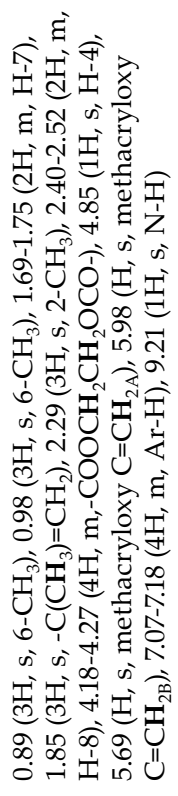 & 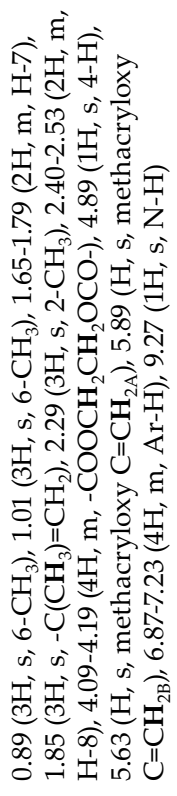 & 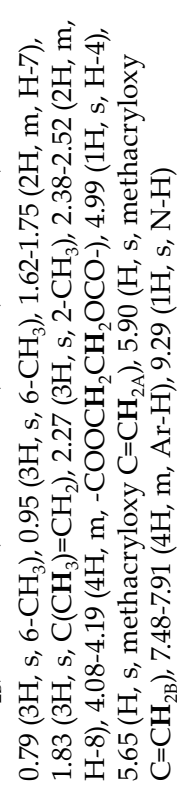 & 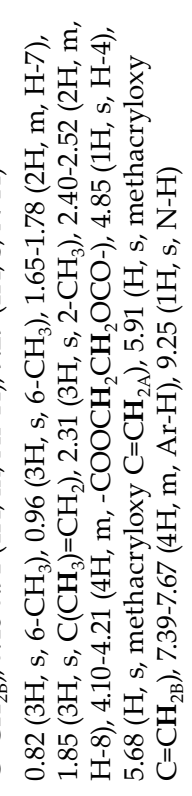 & 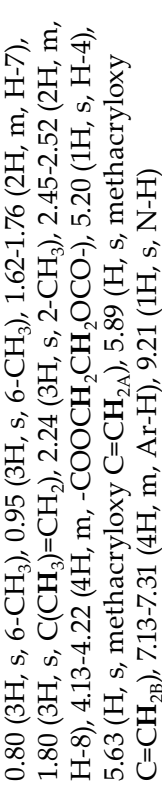 \\
\hline$\because \frac{\widehat{T}}{\overparen{E}}$ & 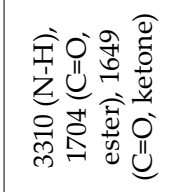 & 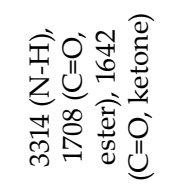 & 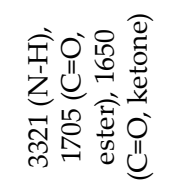 & 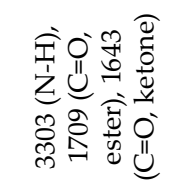 & 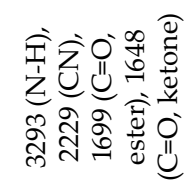 & 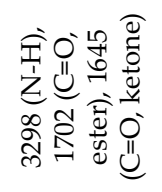 \\
\hline 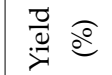 & 므 & $R$ & $\stackrel{12}{1}$ & N & 8 & $\stackrel{\infty}{\wedge}$ \\
\hline $\begin{array}{l}\text { : } 00 \\
\dot{\vec{g}}\end{array}$ & $\begin{array}{l}\stackrel{0}{n} \\
\stackrel{1}{1} \\
\stackrel{n}{n}\end{array}$ & 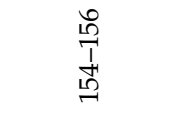 & 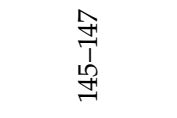 & 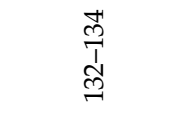 & \begin{tabular}{l}
$\stackrel{9}{+}$ \\
$\frac{1}{\exists}$ \\
\multirow{J}{*}{}
\end{tabular} & 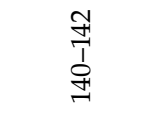 \\
\hline & 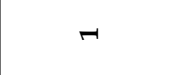 & $N$ & $m$ & A & n & \\
\hline
\end{tabular}


was then dissected parallel to the longitudinal muscle wall. One muscle strip, approximately 15-20 $\mathrm{mm}$ long and $2 \mathrm{~mm}$ wide, was obtained and allowed to equilibrate for a period of $60 \mathrm{~min}$ in $20 \mathrm{~mL}$ organ bath filled with Krebs-Henseleit solution (KHS). The composition of the $\mathrm{Ca}^{2+}$-free Krebs solution was as follows (in $\mathrm{mmol} \mathrm{L}^{-1}$ ): $\mathrm{NaCl} 118 ; \mathrm{KCl} 4.7$; $\mathrm{NaHCO}_{3} 25 ; \mathrm{MgCl}_{2} 0.54 ; \mathrm{NaH}_{2} \mathrm{PO}_{4} 0.9$; glucose 10.04 . The solution was gassed with $95 \% \mathrm{O}_{2}$ and $5 \% \mathrm{CO}_{2}$ during the study and temperature was maintained at $37{ }^{\circ} \mathrm{C}$ by a thermoregulated water circuit. The $\mathrm{pH}$ of the saturated solution was 7.4. Each strip was connected to a force transducer (FDT 10-A, May IOBS 99, COMMAT Iletisim Co., Turkey) for the measurement of isometric force, which was continuously displaced and recorded on an online computer via a four-channel transducer data acquisition system (MP30B-CE, BIOPAC Systems Inc., USA) using software (BSL PRO v 3.6.7, BIOPAC Systems Inc. Santa Barbara, CA, USA) which had the capacity to analyse the data. After mounting, each strip was allowed to equilibrate with a basal tension of $1 \mathrm{~g}$ for $60 \mathrm{~min}$. KHS was replaced with fresh solution every 15 min during that period.

To eliminate that the relaxation induced by the test compounds was due to an interaction with cyclooxygenase, potassium channels, adrenergic or nitric oxide pathways, all experiments were done in the presence of indomethacin (COX inhibitor, $10^{-5} \mathrm{~mol} \mathrm{~L}^{-1}$ ), tetraethylammonium chloride (non-specific $\mathrm{K}^{+}$channel blocker, $10^{-4} \mathrm{~mol} \mathrm{~L}^{-1}$ ), guanethidine (adrenergic nerve blocker, $10^{-6} \mathrm{~mol} \mathrm{~L}^{-1}$ ) and $\mathrm{N} \omega$-nitro- $L$-arginine methyl ester hydrochloride (nitric oxide synthase inhibitor, $10^{-4} \mathrm{~mol} \mathrm{~L}^{-1}$ ).

When $\mathrm{Ca}^{2+}\left(2.5 \mathrm{mmol} \mathrm{L}^{-1}\right)$ was added to the organ bath, a contraction developed. At the plateau level of contraction, compounds DHP1-DHP6 $\left(10^{-8}-10^{-4} \mathrm{~mol} \mathrm{~L}^{-1}\right)$ and nifedipine $\left(10^{-10}-10^{-7} \mathrm{~mol} \mathrm{~L}^{-1}\right)$ were applied. Concentration-relaxation relationship for compounds and nifedipine was observed by adding them into the bath in a cumulative manner. Responses to the test compounds and nifedipine were expressed as percentage of the precontraction using $\mathrm{Ca}^{2+}\left(2.5 \mathrm{mmol} \mathrm{L}^{-1}\right)$. The muscle relaxant activities of DHP1-DHP6 and of $\mathrm{NIF}$, as a reference, were evaluated by measuring the values of maximum relaxant effects $\left(E_{\max }, \%\right)$ and the negative logarithm of the half-maximal effective concentration $E C_{50}$ (in mol L $\left.{ }^{-1}\right)\left(\mathrm{pD}_{2}\right)$ on isolated rabbit gastric fundus smooth muscle strips according to the method reported in the literature (13). The cited values were calculated from the concentration-response curve obtained in each experiment, as predicted from the Scatchard equation for drug-receptor interaction, where:

response/concentration $=\left(1 / E C_{50}\right) \times$ response + maximum response $/ E C_{50}$

All data are expressed as mean \pm standard error. Statistical comparison between the groups was performed using the Mann-Whitney U-test and $p<0.05$ indicated statistical significance (Vaghy, 1987 \#1030).

Dimethyl sulphoxide (DMSO) was also tested in $\mathrm{Ca}^{2+}\left(2.5 \mathrm{mmol} \mathrm{L}^{-1}\right)$ pre-contracted strips. The compounds were dissolved in dimethyl sulfoxide (DMSO) $(<0.01 \%)$. These concentrations of DMSO had no effect on gastric fundus smooth muscle strips pre-treated with $\mathrm{Ca}^{2+}\left(2.5 \mathrm{mmol} \mathrm{L}^{-1}\right)$.

The study was approved by the Ethics Committee of Gazi University, Faculty of Medicine, Ankara, Turkey. All procedures involving animals and their care were conducted in conformity with international laws and policies. 


\section{Photodegradation studies}

The light cabinet Suntest CPS+ was chosen for the photodegradation experiments. The apparatus is equipped with a xenon lamp able to simulate sunlight. Temperature and irradiation were kept constant inside the cabinet and were measured with an electronic device. A standard filter ID65 provided a spectral window in the range of $300-800 \mathrm{~nm}$, in agreement with option 1 of ICH rules (19). The samples were irradiated under irradiance power of $21 \mathrm{~kJ} \mathrm{~m}^{-2} \mathrm{~min}^{-1}$ and at constant temperature of $25^{\circ} \mathrm{C}$. Parameters for recording the UV spectra were: scan rate $1 \mathrm{~nm} \mathrm{~s}^{-1}$, time response $1 \mathrm{~s}$, spectral band $1 \mathrm{~nm}$, wavelength range $200-450 \mathrm{~nm}$. The spectra were recorded at time 0 and at sequential time points: 1,3 , $5,10,15,20,25,30,35,40,45,50,55,60,70,80,90,100,120,130,140,150,160,170,180,190$, 200, 230, 260, 300, 350 and $420 \mathrm{~min}$. Each photodegradation test was performed six times. The collected spectral data were averaged from six experiments. SD was calculated by MCR elaboration applied to the data.

\section{Chemometric elaboration}

UV spectrophotometric data matrices from the photodegradation experiments were processed by MCR-ALS, a recent chemometric technique allowing the study of a complex chemical process. Its application to UV spectral data can resolve the whole system, estimating the number of components, their pure spectra and concentration profiles. Rate constants $(k)$ are also calculated in the processing of kinetic reactions. Analogously with other multivariate methods, MCR makes it possible to decompose the experimental data matrices into the contributions of individual components. The data matrices contain the recorded absorption spectra as a function of the evolution of the chemical process (time, reaction conditions, etc.). Details on the theory of MCR-ALS and its application on drug matrices are fully described in some papers (23-25).

\section{RESULTS AND DISCUSSION}

\section{Chemistry}

In our previous study, several condensed DHP derivatives were synthesized via a modified Hantzsch reaction, bearing a cyclopentane, cyclohexane or tetrahydrothiopene ring with a bulky and lipophilic moiety (3-pyridylmethyl) in the ester group (13). Hantzsch reaction is the one-pot classical method for the synthesis of 1,4-DHPs, which involves cyclocondensation of an aldehyde, two equivalents of a 1,3-dicarbonyl compound and ammonia, generally in refluxing ethanol. Depending on the reaction conditions, long reaction times, low yields and unexpected products can occur $(26,27)$.

In this work, target compounds were achieved by the reaction of 4,4-dimethyl-1,3-cyclohexanedione, substituted benzaldehyde, 2-(methacryloyloxy)ethyl acetoacetate and ammonium acetate in ethanol, according to a modified Hantzsch reaction, by adopting a microwave-assisted one-pot method. Microwave (MW) irradiation represents a novelty of the synthetic strategy due to its ability of reducing reaction times, improving yields and simplifying the work-up processes $(28,29)$. The synthetic route used is outlined in Scheme 1. 
<smiles>[R]c1cccc(COCCOC(=O)C(=O)OCCOC(=O)C(=C)C)c1C1C(C(=O)OCCOC(C)=O)=C(C)NC2=C1C(=O)C(C)(CC(C)C)CC2</smiles>

Scheme 1.

Structures of all compounds were elucidated by spectral methods (IR, ${ }^{1} \mathrm{H}$ NMR, ${ }^{13} \mathrm{C}$ NMR and mass spectrometry) and confirmed by elemental analysis. In the IR spectra, a characteristic N-H stretching band appeared at about $3300 \mathrm{~cm}^{-1}$. Ester and ketone $\mathrm{C}=\mathrm{O}$ stretching bands were seen at about 1700 and $1650 \mathrm{~cm}^{-1}$, respectively. Also, the characteristic stretching band of cyano group in the IR spectrum of DHP5 was observed at $2229 \mathrm{~cm}^{-1}$.

In the ${ }^{1} \mathrm{H}$ NMR spectra, signals of methyl protons at the 6-position of the hexahydroquinoline ring were observed at $0.79-1.01 \mathrm{ppm}$, separately as singlets. The characteristic two signals of the diastereotopic methylidene protons of the ester group were at 5.63-5.98 ppm, while the N-H proton signal was observed at 9.15-9.29 ppm. Chemical shifts of the aromatic, aliphatic and DHP ring protons were seen at expected values.

The ${ }^{13} \mathrm{C}$ NMR spectra of the compounds displayed the appropriate number of resonances, which exactly fitted the number of carbon atoms. The signal of the carbonyl group at C-5 of the hexahydroquinoline ring appeared at about 200 ppm while the ester carbonyl groups were seen close to $167 \mathrm{ppm}$. The effect of resonance and the inductive effect of nitrogen atom caused a great difference in the chemical shift between $\mathrm{sp}^{2}$ hybridized carbons of the DHP ring, as the C-2 and C-8a were observed more deshielded at around 150 ppm, while C-3 and C-4a appeared at 102 and 109 ppm, resp. The peaks of vinyl carbons of the ester group were seen at about 126 and $136 \mathrm{ppm}$. Two characteristic signals of aliphatic carbons attached to oxygens in methacryloyloxy ester (ester adjacent aliphatics) appeared at around 63 and 61 ppm. In addition, the signal of the cyano group (CN) in DHP5 appeared at 111 ppm. ${ }^{13} \mathrm{C}$ NMR chemical shift data of DHP1-DHP6 are given in Table II.

Mass spectra of the compounds were recorded via the electrospray ionization technique. The quasimolecular ions created by the addition of sodium ion $[\mathrm{M}+\mathrm{Na}]^{+}$were observed in the spectra of all compounds. Cleavage of the ester group and the phenyl ring from the parent molecule are further the most observed fragmentations. The isotope effect of chlorine atom appeared obviously in DHP2, carrying one chlorine atom, as [M+Na+2 $]^{+}$ with a relative ratio $66 \%$, while in DHP6, with two chlorine atoms, observed as two peaks $[\mathrm{M}+\mathrm{Na}+2]^{+}$and $[\mathrm{M}+\mathrm{Na}+4]^{+}$with relative ratios 66 and $11 \%$, respectively.

\section{Pharmacological activity}

The muscle relaxant activities of the new DHPs and of NIF, as a reference, were evaluated by measuring the values of maximum relaxant effects $\left(E_{\max }, \%\right)$ and the negative logarithm of $E C_{50}$ (in mol L-1) $\left(\mathrm{pD}_{2}\right.$ ) on isolated rabbit gastric fundus smooth muscle strips. 


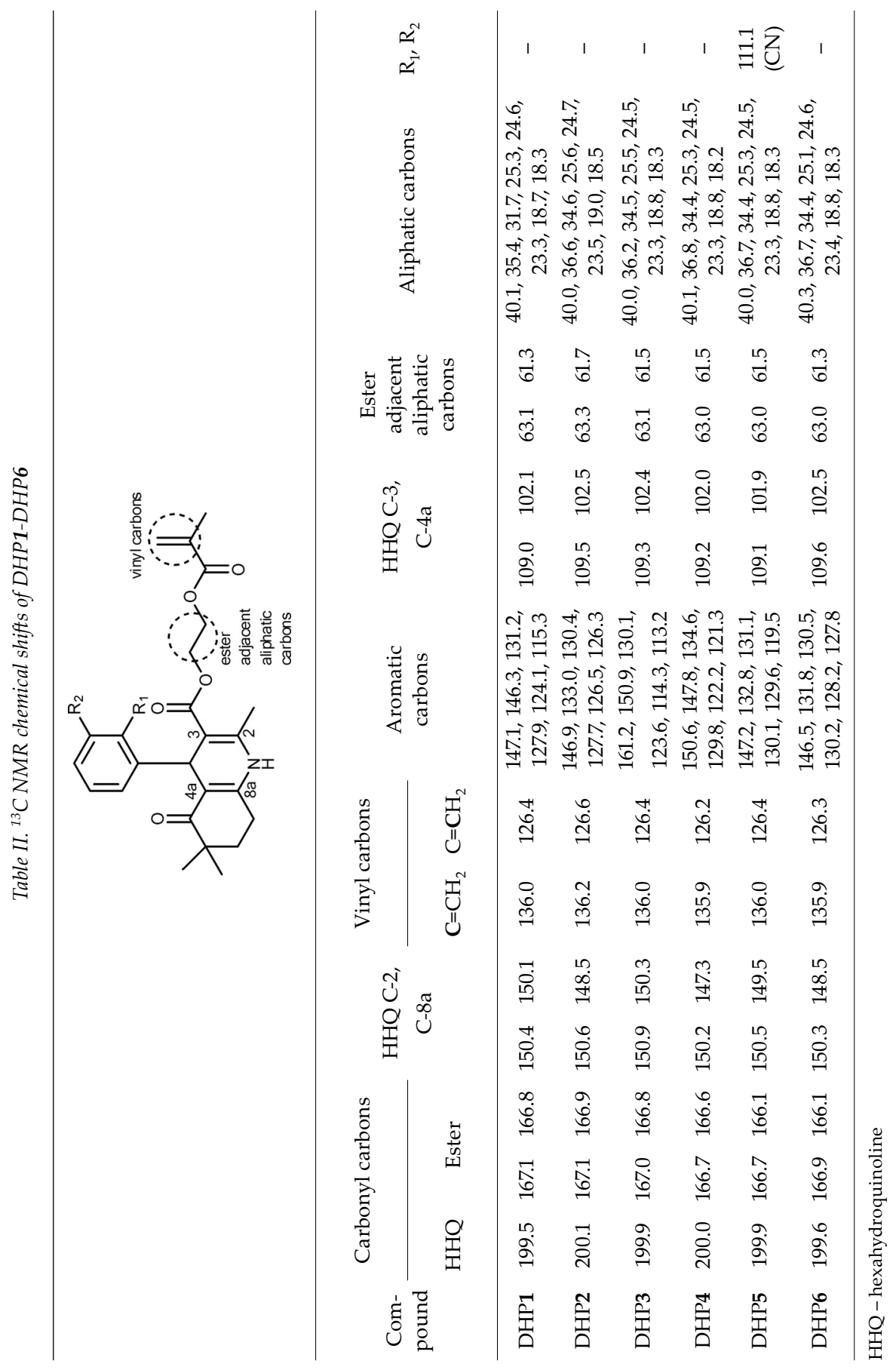


Table III. Chemical structures and maximum relaxant responses $\left(\mathrm{E}_{\text {max }}\right)$ and $p \mathrm{D}_{2}$ values of DHP1-DHP6 and NIF on isolated rabbit gastric fundus smooth muscle strips

\begin{tabular}{clccc}
\hline & & \\
\hline $\mathrm{DHP}$ & $\mathrm{R}_{1}$ & $\mathrm{R}_{2}$ & $E_{\max }(\%)^{\mathrm{a}}$ & \\
\hline 1 & $\mathrm{~F}$ & $\mathrm{H}$ & $75.09 \pm 5.95^{*}$ & $5.19 \pm 0.47^{*}$ \\
2 & $\mathrm{H}$ & $\mathrm{Cl}$ & $66.83 \pm 4.53^{*}$ & $5.29 \pm 0.36^{*}$ \\
3 & $\mathrm{H}$ & $\mathrm{NO}$ & $67.98 \pm 6.58^{*}$ & $5.22 \pm 0.52^{*}$ \\
4 & $\mathrm{H}$ & $\mathrm{CN}$ & $79.01 \pm 4.03^{*}$ & $5.28 \pm 0.30^{*}$ \\
5 & $\mathrm{Cl}$ & $68.48 \pm 1.88^{*}$ & $5.46 \pm 0.03^{*}$ \\
6 & $\mathrm{Cl}$ & - & $98.92 \pm 0.83$ & $7.68 \pm 0.08$ \\
$\mathrm{NIF}$ & - & & \\
\hline
\end{tabular}

Relaxation is expressed as percentage of pre-contraction induced by $\mathrm{Ca}^{2+}\left(2.5 \mathrm{mmol} \mathrm{L}^{-1}\right)$.

$\mathrm{p} D_{2}$ is a negative logarithm of the concentration for the half-maximal response $E C_{50}\left(\mathrm{~mol} \mathrm{~L}^{-1}\right)$.

${ }^{\mathrm{a}}$ Mean $\pm \mathrm{SEM}, n=6$.

Significant difference compared to NIF: ${ }^{*} p<0.05$.

Chemical structures of the analyzed compounds and the relative $E_{\max }$ and $\mathrm{p} D_{2}$ values are given in Table III.

The results indicated that all the tested compounds exerted concentration-dependent relaxation on gastric fundus smooth muscle strips pre-treated with $\mathrm{Ca}^{2+}\left(2.5 \mathrm{mmol}^{-1}\right)$ in the following efficacy order: NIF $>$ DHP4 $\geq$ DHP1 $\geq$ DHP5 $>$ DHP6 $=$ DHP3 $=$ DHP2. These results show that the studied compounds exhibit comparable mutual efficacy and potency; however, in comparison with NIF, the efficacy is on average significantly lower, while the potency is significantly higher, possibly due to the blockade of calcium channels.

Given that the difference between the compounds is the aromatic substitution pattern, this suggests that the substituents on the phenyl ring play a key role in the ability of these compounds to possess myorelaxant effects. When the obtained results are analyzed in terms of the substituents on the phenyl ring at the C-4 position of DHP, the most active derivative was found to be the $3-\mathrm{NO}_{2}$ analogue (DHP4). Regarding the $\mathrm{R}_{2}$ substituent, the compounds bearing strong electron withdrawing groups $\left(\mathrm{NO}_{2}, \mathrm{CN}\right)$ were observed to be the most active derivatives. Displacement of the fluorine atom from meta $\left(\mathrm{R}_{2}\right)$ to ortho $\left(\mathrm{R}_{1}\right)$ position increased the preferential activity. Introduction of the second chlorine atom on the phenyl ring mediated no significant change in myorelaxant activity. 
It was also proven that there was no contribution of cyclooxygenase, adrenergic and nitric oxide pathways, ATP sensitive $\mathrm{K}^{+}$channels and Ca-activated $\mathrm{K}^{+}$channels to the myorelaxant effects of these compounds.

\section{Photostability study}

All drugs belonging to the DHP class show a remarkable sensitivity to light, posing serious limits to easy handling of their pharmaceutical preparations. Several reports evidence the photolability of DHPs used in therapy (15-18). Photodegradation tests of the newly synthesized compounds were performed with the aim to identify DHP structures more photostable than the currently known congeners. DHP molecules more resistant to light could be candidates for preparing liquid formulations of these drugs, currently hindered by their photolability.

In our previous studies (14-16, 30-32), the influence of sample concentration on the photodegradation profile was demonstrated. However, in this study, degradation kinetics and the number of photoproducts remained unchanged with increasing concentration of analytes. Thus, photostability studies were applied to standard ethanolic solutions of the synthesized DHPs at a concentration of $20 \mu \mathrm{g} \mathrm{mL}^{-1}$, which was optimal for spectrophotometric measurements at time 0 and at several time points, as described above. Stress tests were performed in agreement with option 1 of ICH rules (19).

All samples, except sample DHP4, showed the same degradation profile. Fig. 1 shows the spectral sequences for samples DHP1 and DHP4, as representatives. Gradual decreases of absorbance signals of the DHP chromophoric group were observed in regions 340-400 and 230-250 nm. Simultaneous appearance and increase of a new peak in region 260-310 nm was observed, which was due to the formation of the pyridine group, in agreement with our previous studies (14-16). The sequence of the recorded spectra for all studied compounds evidenced the formation of photodegradation products. The collected spectra furnished the temporal spectral evolution of the system without any specifications about all species involved in the chemical process. Characterization of the components involved in the photodegradation process, therefore, required the application of chemometric methods to the data matrices. According to our previous work (14), the residual concentration of the target compounds was determined by applying the MCR algorithm to the spectral data.
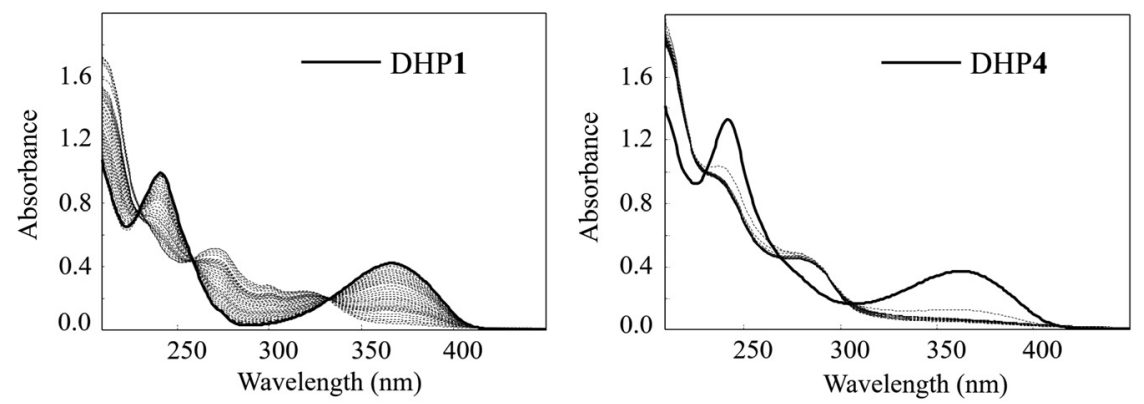

Fig. 1. Absorbance spectra of DHP1 and DHP4 solutions $(20 \mu \mathrm{g} \mathrm{mL}-1)$ during irradiation. 


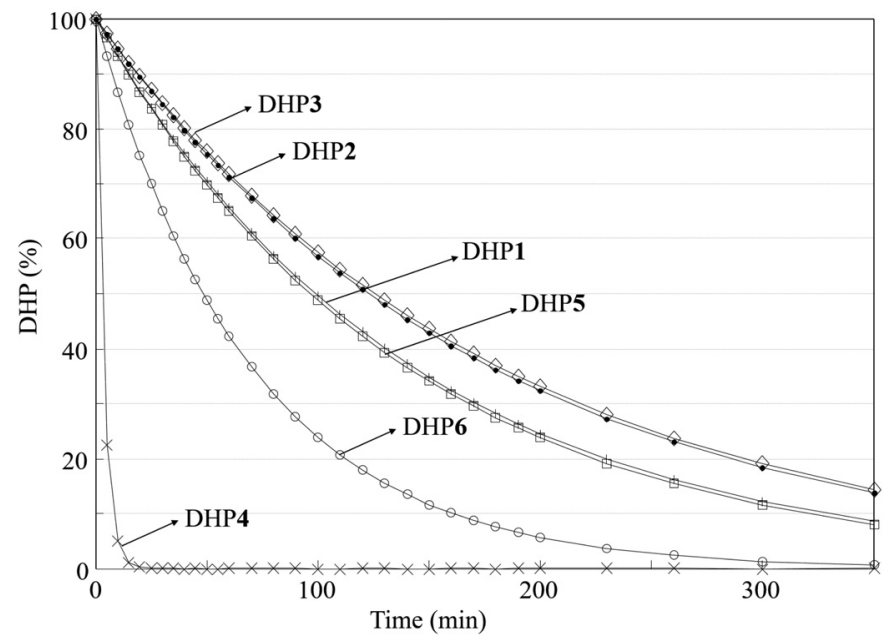

Fig. 2. Photodegradation profiles of all DHP molecules $\left(20 \mu \mathrm{g} \mathrm{mL} \mathrm{L}^{-1}\right)$ exposed to light.

This chemometric procedure was adopted for its ability to determine, during the entire photodegradation process, the number of involved species and their concentration and at the same time to plot their absorbance spectra (20-22).

Fig. 2 shows the photodegradation profile of all the studied DHPs, obtained by plotting residual concentrations vs. sequential irradiation times throughout the photodegradation experiments.

All tested compounds were confirmed to be sensitive to light, showing $10 \%$ degradation in less than twenty minutes of irradiation. Although the degradation process was still fast, the new molecules were much more stable than NIF. This result is very important when considering the toxicity of DHP by-products. Phototoxic skin responses after systemic administration of photosensitive drugs have been reported (33). Exposure to light of DHP has been demonstrated to cause significant production of singlet oxygen, superoxide, or both, indicating their phototoxic potential of inducing dermatitis.

Spectral data collected during the photodegradation tests, an average of six experiments, were processed by MCR-ALS to calculate the concentration profiles of all the species detected during the degradation process and to predict their absorbance spectra. Standard deviation of the found concentrations was between $0.01-0.09 \mu \mathrm{g} \mathrm{mL} \mathrm{m}^{-1}$. Fig. 3 shows the estimated concentration profiles of DHP1 and DHP4, with their by-products and the respective absorbance spectra.

All the photodegradation processes followed first-order kinetics, according to the equation:

$$
\log (\% \mathrm{DHP})=-k \cdot t+2
$$

in which \% DHP was the residual drug percentage, $k$ the rate constant, $t$ the time (s) and value 2 represented the logarithm of the initial concentration (100\%). The time to cause $10 \%$ degradation $\left(t_{0,1}\right)$, the number of the involved species in the kinetic process and lack 

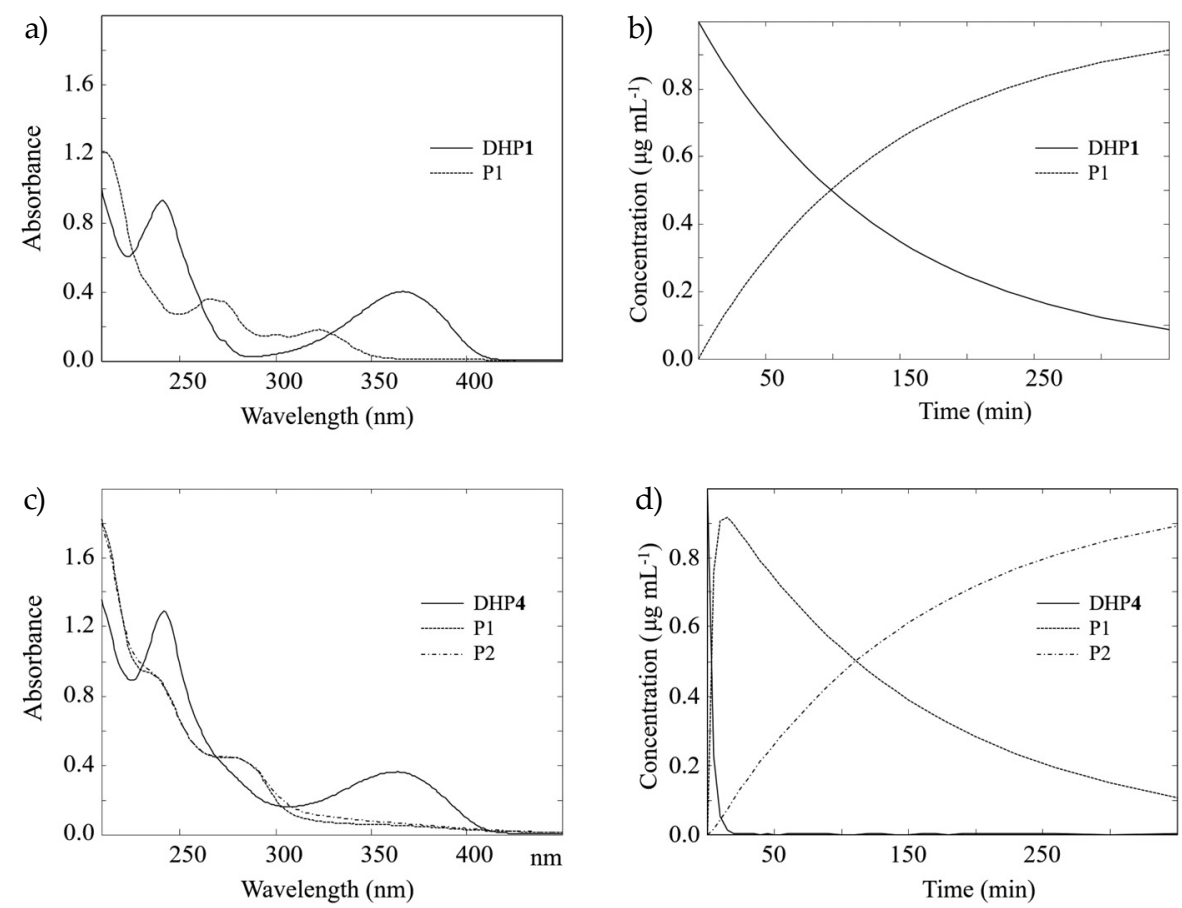

Fig. 3. Absorbance spectra and concentration profiles of DHP1 (a and b, resp.) and DHP4 (c and d, resp.) and their by-products from MCR elaboration.

of fit (LOF, \%) were calculated as well. Singular value decomposition (SVD) techniques were applied to spectral data matrices to define the number of the species involved in the photodegradation process. SVD is a mathematical procedure commonly used in the analysis

Table IV. Degradation kinetics parameters for DHP1-DHP6

\begin{tabular}{ccccc}
\hline DHP & No. species & $\begin{array}{c}k \pm \mathrm{SD}) \times 10^{3} \\
\left(\mu \mathrm{g} \mathrm{mL} \mathrm{min}^{-1}\right)^{\mathrm{a}}\end{array}$ & LOF $(\%)$ & $t_{0.1}(\mathrm{~min})$ \\
\hline 1 & 2 & $7.00 \pm 0.09$ & 5.48 & 15.30 \\
2 & 2 & $5.70 \pm 0.02$ & 2.39 & 19.27 \\
3 & 2 & $5.50 \pm 0.01$ & 0.61 & 19.54 \\
4 & 3 & $298.60 \pm 23.90$ & 3.83 & 0.67 \\
5 & 2 & $6.40 \pm 0.02$ & & 15.25 \\
6 & 2 & $7.20 \pm 0.05$ & 4.16 & 7.42 \\
\hline
\end{tabular}

No. species - number of species involved in the kinetic process, $k$ - photodegradation rate constant, LOF - lack of fit, $t_{0.1}$ - time to cause $10 \%$ degradation

${ }^{a}$ Number of replicate measurements, $n=6$. 
of spectroscopic data to differentiate signals from noise and to reduce the dimensionality of subsequent least-squares fits. SVD takes data from experiments under different conditions, such as time or $\mathrm{pH}$, and represents them by two sets of vectors weighted by their corresponding singular values. Table IV summarizes all the calculated kinetic parameters, as an average of six determinations. Very low values of variance were found in all the cases.

Formation of a single photoproduct (P1), corresponding to the pyridine derivative according to the literature (14-18), was calculated for all the studied compounds. Only compound DHP4 showed different behavior with the probable formation of the first degradation product (P1), followed by a secondary photoproduct (P2), as indicated by the number of species involved in the kinetic process, obtained by SVD data elaboration, and by the presence of two $k$ values. Fast and complex degradation of compound DHP4 was probably due to the presence of the $\mathrm{NO}_{2}$ group on the phenyl ring, promoting an intramolecular disproportionation reaction, followed by aromatization of the pyridinic ring, in agreement with the results reported in previous works $(14,16)$.

\section{CONCLUSIONS}

An easy, rapid and convenient method for the preparation of condensed 1,4-DHPs via a modified Hantzsch reaction under MW irradiation is reported. Pharmacological evaluation showed good relaxing effects on isolated rabbit gastric fundus smooth muscles, due to the blockade of $\mathrm{Ca}^{2+}$ channels, with a mechanism similar to that of NIF. A long-chain alkyl moiety [2-(methacryloyloxy)ethyl] as the ester function in combination with electronwithdrawing substituents at the phenyl ring led to an increase in pharmacological activity.

Photostability of the synthesized compounds was also evaluated by a joint spectrophotometric and chemometric approach with the aim to select light-stable drug candidates endowed with high pharmacological activity. The obtained results demonstrated a significant increase of the photostability with halogen as substituent $R_{2}$ of the phenyl ring with simultaneous absence of substituent in $R_{1}$ position.

Acknowledgements. - The authors gratefully acknowledge financial support provided by the Scientific Research Fund of Hacettepe University, Turkey, through Project 013.01.003.001.

\section{REFERENCES}

1. G. W. Zamponi, J. Striessnig, A. Koschak and A. C. Dolphin, The physiology, pathology, and pharmacology of voltage-gated calcium channels and their future therapeutic potential, Pharmacol. Rev. 67 (2015) 821-870; DOI: 10.1124/pr.114.009654.

2. E. Carosati, P. Ioan, M. Micucci, F. Broccatelli, G. Cruciani, B. S. Zhorov, A. Chiarini and R. Budriesi, 1,4-Dihydropyridine scaffold in medicinal chemistry, the story so far and perspectives (part 2): Action in other targets and antitargets, Curr. Med. Chem. 19 (2012) 4306-4323; DOI: 10.2174/092986712802884204.

3. V. M. Gadotti, C. Bladen, F. X. Zhang, L. Chen, M. G. Gündüz, R. Şimşek, C. Şafak and G. W. Zamponi, Analgesic effect of a broad-spectrum dihydropyridine inhibitor of voltage-gated calcium channels, Pflug. Arch. Eur. J. Phys. 467 (2015) 2485-2493; DOI: 10.1007/s00424-015-1725-1. 
4. P. Ioan, E. Carosati, M. Micucci, G. Cruciani, F. Broccatelli, B. S. Zhorov, A. Chiarini and R. Budriesi, 1,4-Dihydropyridine scaffold in medicinal chemistry, the story so far and perspectives (part 1): Action in ion channels and GPCRs, Curr. Med. Chem. 18 (2011) 4901-4922; DOI: 10.2174/092986711797535173.

5. N. Edraki, A. R. Mehdipour, M. Khoshneviszadeh and R. Miri, Dihydropyridines: evaluation of their current and future pharmacological applications, Drug Discov. Today 14 (2009) 1058-1066; DOI: 10.1016/j.drudis.2009.08.004.

6. D. Takahashi, L. Oyunzul, S. Onoue, Y. Ito, S. Uchida, R. Simsek, M. G. Gunduz, C. Safak and S. Yamada, Structure-activity relationships of receptor binding of 1,4-dihydropyridine derivatives, Biol. Pharm. Bull. 31 (2008) 473-479; DOI: 10.1248/bpb.31.473.

7. M. Hosseini, R. Miri, M. Amini, H. Mirkhani, B. Hemmateenejad, S. Ghodsi, E. Alipour and A. Shafiee, Synthesis, QSAR and calcium channel antagonist activity of new 1,4-dihydropyridine derivatives containing 1-methyl-4,5-dichloroimidazolyl substituents, Arch. Pharm. 340 (2007) 549556; DOI: 10.1002/ardp.200600211.

8. R. A. Coburn, M. Wierzba, M. J. Suto, A. J. Solo, A. M. Triggle and D. J. Triggle, 1,4-Dihydropyridine antagonist activities at the calcium-channel - a quantitative structure activity relationship approach, J. Med. Chem. 31 (1988) 2103-2107; DOI: 10.1021/jm00119a009.

9. C. Bladen, V. M. Gadotti, M. G. Gündüz, N. D. Berger, R. Şimşek, C. Şafak and G. W. Zamponi, 1,4-Dihydropyridine derivatives with T-type calcium channel blocking activity attenuate inflammatory and neuropathic pain, Pflug. Arch. Eur. J. Phys. 467 (2014) 1237-1247; DOI: 10.1007/s00424014-1566-3.

10. C. Bladen, M. G. Gündüz, R. Şimşek, C. Şafak and G. W. Zamponi, Synthesis and evaluation of 1,4-dihydropyridine derivatives with calcium channel blocking activity, Pflug. Arch. Eur. J. Phys. 466 (2014) 1355-1363; DOI: 10.1007/s00424-013-1376-z.

11. C. Safak and R. Simşek, Fused 1,4-dihydropyridines as potential calcium modulatory compounds, Mini Rev. Med. Chem. 6 (2006) 747-755; DOI: 10.2174/138955706777698606.

12. R. Simsek, G. S. Oztürk, I. M. Vural, M. G. Gündüz, Y. Sarioglu and C. Safak, Synthesis and calcium modulatory activity of 3-alkyloxy-carbonyl-4-(disubstituted)aryl-5-oxo-1,4,5,6,7,8-hexa-hydroquinoline derivatives, Arch. Pharm. 341 (2008) 55-60; DOI: 10.1002/ardp.200700087.

13. C. Safak, M. G. Gündüz, S. Ö. İlhan, R. Şimşek, F. İşli, Ş. Yıldırım, G. S. Öztürk Fincan, Y. Sarıŏlu and A. Linden, Synthesis and myorelaxant activity of fused 1,4-dihydropyridines on isolated rabbit gastric fundus, Drug Dev. Res. 73 (2012) 332-342; DOI: 10.1002/ddr.21024.

14. G. Ioele, M. G. Gündüz, M. De Luca, R. Şimşek, C. Şafak, R. Muzzalupo and G. Ragno, Photodegradation studies of 1,4-dihydropyridine compounds by MCR analysis on UV spectral data, Future Med. Chem. 8 (2016) 107-115; DOI: 10.4155/fmc.15.172.

15. G. Ioele, F. Oliverio, I. Andreu, M. De Luca, M. A. Miranda and G. Ragno, Different photodegradation behavior of barnidipine under natural and forced irradiation, J. Photochem. Photobiol. A Chem. 215 (2010) 205-213; DOI: 10.1016/j.jphotochem.2010.08.019.

16. G. Ioele, M. De Luca, F. Oliverio and G. Ragno, Prediction of photosensitivity of 1,4-dihydropyridine antihypertensives by quantitative structure-property relationship, Talanta 79 (2009) 14181424; DOI: 10.1016/j.talanta.2009.06.009.

17. G. Ragno, C. Vetuschi, A. Risoli and G. Ioele, Application of a classical least-squares regression method to the assay of 1,4-dihydropyridine antihypertensives and their photoproducts, Talanta 59 (2003) 375-382; DOI: 10.1016/S0039-9140(02)00526-X.

18. G. Ragno, M. Veronico and C. Vetuschi, Gas chromatographic and UV derivative determination of nitrendipine and its photodegradation product, Int. J. Pharm. 99 (1993) 351-355; DOI: 10.1016/03785173(93)90380-X. 
19. International Conference on Harmonisation of Technical Requirements for Registration of Pharmaceuticals for Human Use, ICH Q1A(R2) Stability Testing of New Drug Substances and Products, IFPMA, Geneva 2003.

20. M. De Luca, G. Ragno, G. Ioele and R. Tauler, Multivariate curve resolution of incomplete fused multiset data from chromatographic and spectrophotometric analyses for drug photostability studies, Anal. Chim. Acta 837 (2014) 31-37; DOI: 10.1016/j.aca.2014.05.056.

21. M. De Luca, W. Terouzi, F. Kzaiber, G. Ioele, A. Oussama and G. Ragno, Classification of moroccan olive cultivars by linear discriminant analysis applied to ATR-FTIR spectra of endocarps, Int. J. Food Sci. Technol. 47 (2012) 1286-1292; DOI: 10.1111/j.1365-2621.2012.02972.x.

22. M. De Luca, S. Mas, G. Ioele, F. Oliverio, G. Ragno and R. Tauler, Kinetic studies of nitrofurazone photodegradation by multivariate curve resolution applied to UV-spectral data, Int. J. Pharm. 386 (2010) 99-107; DOI: 10.1016/j.ijpharm.2009.11.003.

23. A. Smilde, R. Bro and P. Geladi, Multi-Way Analysis: Applications in the Chemical Sciences, Wiley, Chichester (UK) 2004.

24. S. Mas, A. de Juan, S. Lacorte and R. Tauler, Photodegradation study of decabromodiphenyl ether by UV spectrophotometry and a hybrid hard- and soft-modelling approach, Anal. Chim. Acta 618 (2008) 18-28; DOI: 10.1016/j.aca.2008.04.044.

25. R. Tauler, M. Maeder and A. de Juan, Multiset Data Analysis: Extended Multivariate Curve Resolution, in Comprehensive Chemometrics, Chemical and Biochemical Data Analysis, $1^{\text {st }}$ ed. (Eds. S. D. Brown, R. Tauler and B. Walczak), Vol 2, Elsevier, London 2009, pp. 473-505.

26. V. G. Santos, M. N. Godoi, T. Regiani, F. H. Gama, M. B. Coelho, R. O. de Souza, M. N. Eberlin and S. J. Garden, The multicomponent Hantzsch reaction: Comprehensive mass spectrometry monitoring using charge-tagged reagents, Chem. Eur. J. 20 (2014) 12808-12816; DOI: 10.1002/ chem.201303065.

27. K. A. Undale, Y. Park, K. Park, D. H. Dagade and D. M. Pore, A revisit to the Hantzsch reaction: Unexpected formation of tetrahydrobenzo[b]pyrans beyond polyhydroquinolines, Synlett 6 (2011) 791-796; DOI: 10.1055/s-0030-1259924.

28. A. Debache, W. Ghalem, R. Boulcina, A. Belfaitah, S. Rhouati and B. Carboni, An efficient one-step synthesis of 1,4-dihydropyridines via a triphenylphosphine-catalyzed three-component Hantzsch reaction under mild conditions, Tetrahedron Lett. 50 (2009) 5248-5250; DOI: 10.1016/j.tetlet.2009.07.018.

29. A. Saini, S. Kumar and J. S. Sandhu, Hantzsch reaction: Recent advances in Hantzsch 1,4-dihydropyridines, J. Sci. Ind. Res. 67 (2008) 95-111.

30. G. Ioele, M. De Luca and G. Ragno, Photostability of barnidipine in combined cyclodextrin-in-liposome matrices, Future Med. Chem. 6 (2014) 35-43; DOI: 10.4155/fmc.13.187.

31. G. Ragno, A. Risoli, G. Ioele, E. Cione and M. De Luca, Photostabilization of 1,4-dihydropyridine antihypertensives by incorporation into beta-cyclodextrin and liposomes, J. Nanosci. Nanotech. 6 (2006) 2979-2985; DOI: 10.1166/jnn.2006.407.

32. G. Ragno, M. Veronico and C. Vetuschi, Analysis of nimodipine and its photodegradation product by derivative spectrophotometry and gas chromatography, Int. J. Pharm. 119 (1995) 115-119; DOI: 10.1016/0378-5173(94)00399-P.

33. S. Onoue, N. Igarashi, Y. Yamauchi, N. Murase, Y. Zhou, T. Kojima, S. Yamada and Y. Tsuda, In vitro phototoxicity of dihydropyridine derivatives: A photochemical and photobiological study, Eur. J. Pharm. Sci. 33 (2008) 262-270; DOI: 10.1016/j.ejps.2007.12.004. 